\title{
Goal attainment in mobility after acute rehabilitation of mobility-restricting paralysis syndromes with regard to the ambulatory therapeutic level of participation NeuroMoves
}

\section{A German national multicenter observational cohort study}

\author{
Andreas Hug $^{1 *}$ (D), Tamara Spingler ${ }^{1}$, Cornelia Hensel $^{1}$, Stefan Fichtner ${ }^{1}$, Tiziana Daniel ${ }^{2}$, Laura Heutehaus ${ }^{1}$,
} Michel Wensing ${ }^{2}$, Rüdiger Rupp ${ }^{1}$ and Norbert Weidner ${ }^{1}$

\begin{abstract}
Background: A central goal of rehabilitation in patients with paralysis syndromes after stroke or spinal cord injury $(\mathrm{SCl})$ is to restore independent mobility as a pedestrian or wheelchair user. However, after acute rehabilitation, the mobility frequently deteriorates in the ambulatory setting, despite the delivery of rehabilitative interventions such as physical therapy or the prescription of assistive devices. The aim of the NeuroMoves study is to identify factors that are associated with changes of mobility in the ambulatory setting after acute inpatient rehabilitation, with a particular focus on participation according to the ICF (International Classification of Functioning, Disability and Health).

Methods: The NeuroMoves study is intended as a national multicenter observational cohort study with 9 clinical sites in Germany. A total of 500 patients with mobility-restricting paralysis syndromes (i.e. stroke or SCl) are to be recruited during acute inpatient rehabilitation prior to discharge to the ambulatory setting. Patients will have 8 months of follow-up in the ambulatory setting. Three study visits at the clinical sites (baseline, midterm, and final) are planned at 4-months intervals. The baseline visit is scheduled at the end of the acute inpatient rehabilitation. During the visits, demographical data, neurological, functional, quality of life, and implementation measures will be assessed.

At baseline, each study participant receives an activity tracker (sensor for recording ambulatory mobility) along with a tablet computer for home use over the 8 months study duration. While mounted, the activity tracker records mobility data from which the daily distance covered by walking or wheelchair use can be calculated. Customized (Continued on next page)
\end{abstract}

\footnotetext{
* Correspondence: andreas.hug@med.uni-heidelberg.de

${ }^{1}$ Spinal Cord Injury Center, Heidelberg University Hospital, Schlierbacher Landstraße 200a, 69118 Heidelberg, Germany

Full list of author information is available at the end of the article
}

C C The Author(s). 2021 Open Access This article is licensed under a Creative Commons Attribution 4.0 International License, which permits use, sharing, adaptation, distribution and reproduction in any medium or format, as long as you give appropriate credit to the original author(s) and the source, provide a link to the Creative Commons licence, and indicate if changes were made. The images or other third party material in this article are included in the article's Creative Commons licence, unless indicated otherwise in a credit line to the material. If material is not included in the article's Creative Commons licence and your intended use is not permitted by statutory regulation or exceeds the permitted use, you will need to obtain permission directly from the copyright holder. To view a copy of this licence, visit http://creativecommons.org/licenses/by/4.0/ The Creative Commons Public Domain Dedication waiver (http://creativecommons.org/publicdomain/zero/1.0/) applies to the data made available in this article, unless otherwise stated in a credit line to the data. 


\begin{abstract}
(Continued from previous page)
applications on the tablet computer remind the study participants to answer structured questionnaires about their health condition and treatment goals for physical therapy. Using the study participants' tablet, therapists will be asked to answer structured questionnaires concerning treatment goals and therapeutic measures they have applied. The primary analysis concerns the association between mobility (daily distance covered) and the degree of participation-oriented rehab interventions. Further exploratory analyses are planned.

Discussion: The findings could inform healthcare decision-making regarding ambulatory care in Germany focusing on mobility-promoting interventions for patients with mobility-restricting paralysis syndromes.

Study registration: German Clinical Trials Register, DRKS-ID: DRKS00020487 (18.02.2020).

Keywords: Mobility, Participation, Stroke, Spinal cord injury, Physical therapy, Assistive devices, Ambulatory care, ICF
\end{abstract}

\section{Background}

Medical rehabilitation in Germany is largely regulated in a complementary way by two Social Codes (code of social law IX and V). Together with the social legislation for people with disabilities (code IX), the statutory health insurance (SHI) system (code V) aims to prevent, eliminate, reduce, and compensate for limited social participation or mitigate consequences thereof. The legislative wording underscores the importance of social participation in the context of rehabilitation. Within this framework of social legislation and the associated healthcare funds, the reimbursement of therapeutic interventions in medical rehabilitation depends on the type and severity of the health disorder as well as on the rehabilitation potential of the individual subject (e.g. physical therapy, occupational therapy, speech therapy, (neuro-)psychological, socio-medical, and nursing interventions) [1]. 73 million (88\%) of the people in Germany are insured under SHI. By law, they are entitled to healthcare that is adequate, appropriate, and economical. The main principles for the provision of rehabilitation in the German social security system are "rehabilitation before retirement" and "rehabilitation before nursing".

Concerning the setting of care, the German healthcare system is divided into an outpatient (ambulatory) and inpatient (hospital) sector. Ambulatory care is provided by general practitioners, specialists, dentists, and psychotherapists, as well as other healthcare professionals, such as physical therapists, orthopedic technicians, and occupational or speech therapists. Inpatient care is provided by around 1900 hospitals throughout Germany. Only a very small proportion of hospitals are also entitled to provide outpatient care (e.g. University outpatient clinics). Rehabilitation treatment after acute illnesses can be provided on either an outpatient or inpatient basis. For the acute phase of neurological disorders such as stroke or spinal cord injury (SCI), several weeks of inpatient neurorehabilitation in dedicated rehabilitation facilities are usually provided seamlessly after the acute hospital treatment. Due to several limitations concerning the consistency and continuity in the delivery of SHI health services, the subsequent between-sector transition (hospital to ambulatory care) has recently been reformed by legislation ("GKV-Versorgungsstärkungsgesetz"). Since 2017, hospitals have been obliged to implement discharge management programs. However, after hospital discharge, the quality and quantity of indicated neurorehabilitative interventions (e.g. physical therapy) after stroke and SCI is largely unknown. In the ambulatory sector particularly, dedicated health care managers/ coordinators as well as models of multi-professional and interdisciplinary cooperation are missing [1].

Stakeholders of rehabilitation in Germany emphasize that health care interventions such as physical therapy should focus more on improvements in participation [1]. Therapeutic efforts in this regard only seem conceivable by comprehension and application of an integrative biopsychosocial model like the ICF (International Classification of Functioning, Disability and Health; https:// www.who.int/classifications/drafticfpracticalmanual2. pdf?ua=1), which represents a conceptual framework for participation-oriented therapies. Within this biopsychosocial model, patients can be evaluated in a standardized and operationalized fashion. Moreover, rehabilitation procedures, as well as the prescription of mobilitypromoting assistive devices, can be customized through the appreciation of individual and contextual factors [2, 3]. This can be achieved not only on the lowerdimensional level of body structure and function (e.g. reducing muscle tone), but also on the higher-dimensional levels of activities and participation (i.e. walking or mobility by other means, climbing stairs, extending the activity radius beyond the home, or the immediate surroundings [4]).

Frequently, chronic consequences of stroke and SCI lead to a permanent and severe restriction in mobility. Hence, one of the main treatment goals in acute and chronic rehabilitation after stroke and SCI represents the maintenance and improvement of mobility. Unfortunately, after the completion of acute rehabilitation in stroke survivors, the achieved mobility is deteriorating over the following 5 years after hospital discharge [5]. 
Moreover, disability-associated complications such as fractures after falls, or immobilization-related pressure injuries, which make it necessary to seek medical services, are common in the chronic course of stroke and SCI [6-8]. Several, yet only ill-defined implementation factors might contribute to this deterioration of mobility in the ambulatory sector:

1) Insufficient involvement of individual and contextual/environmental patient needs in defining treatment goals. The definition of treatment goals is mainly therapist-centered and on the level of body structure and function, while patients typically define their goals on the level of activities and participation (i.e. in a real-life situation). For example, physical therapists focus on measures aimed at reducing increased muscle tone (body function), while patients want to manage longer distances by foot or wheelchair to do daily errands (activities and participation). Prima facie, these different therapeutic views might lead to unequal expectations of therapists and patients and the impression that patient goals are only insufficiently pursued. In the last consequence, patient satisfaction and rehabilitative treatment success are negatively influenced $[9,10]$.

2) Physical therapy might be methodologically biased towards the level of body structure and function rather than the level of activities and participation. In Germany, physical therapy for patients with neurological disorders is mainly method -/technology-centered (e.g. special physical therapy for the treatment of central nervous system (CNS) disorders or SCI which uses the so-called neurophysiological techniques according to Bobath, Vojta, or Proprioceptive Neuromuscular Facilitation). These therapeutic interventions are reimbursed and operationalized according to the German therapy catalog ("Heilmittelkatalog"). Goal-oriented, therefore method-/technology-independent therapeutic interventions according to internationally consented neuroscientific principles are missing in the German "Heilmittelkatalog" [1, 11].

3) Coordination of rehabilitation-related health care interventions is only insufficiently implemented: Despite discharge management programs that are determined by legal regulation, the provision of mobility-promoting rehabilitative interventions like physical therapy and the prescription of assistive devices are only insufficiently coordinated, particularly in the ambulatory sector $[1,12]$.

4) Lack of indication-specific care pathways for the prescription of mobility-promoting assistive devices [1].

5) Systematic evaluations of goal attainment are not implemented in the current state of care [1].
To the best of our knowledge, there are no systematic analyses in large patient cohorts, neither nationally nor internationally, to investigate the implementation of ambulatory rehabilitation interventions. Moreover, association analyses between ambulatory rehabilitation interventions and pre-specified rehabilitation goals or objectively measured functional mobility outcomes are missing.

The NeuroMoves project aims for a systematic analysis of the current status of rehabilitation care at the transition between the hospital and ambulatory sectors with an emphasis on patient mobility. Moreover, the project intends to identify implementation deficiencies in the ambulatory delivery of rehabilitation services. The target population are people with mobility impairments following stroke or SCI over the first 8 months after acute rehabilitation.

\section{Objectives}

The primary objectives are

1) The incongruence between treatment goals of health care providers (physician, physical therapy, occupational therapy, medical supply store) and patients with paralysis-related limitations of mobility (stroke, SCI) leads to a deterioration of their mobility.

2) Treatment goals of health care providers cannot be effectively achieved because

a. assistive devices are not prescribed/administered according to the patients' needs,

b. physical therapy lacks sufficient participationrelated patient goal orientation

c. coordinated interdisciplinary cooperation of outpatient health care providers related to rehab interventions is missing.

\section{Methods}

The outline of the methods section is oriented on the STROBE (Strengthening the Reporting of Observational Studies in Epidemiology) reporting guideline [13].

\section{Study design}

We use an observational cohort design to follow-up stroke or SCI patients in the ambulatory sector for a fixed period of 8 months. Our main interest is on the organization and current practice of rehab interventions in the ambulatory sector in the real life setting after completion of acute rehabilitation. Therefore, patients are enrolled within 6 weeks after discharge. 


\section{Recruitment}

The target population recruitment takes place in two German regions, in the south and north (Rhein-Neckar region and Schleswig-Holstein/Hamburg states) between May 2020 and December 2021.

\section{Study centers}

To adjust for clustering effects across Germany, four centers are in the north (Schleswig-Holstein and Hamburg) and five centers in the south (Rhein-Neckar area) of Germany. In addition to the coordinating center (Spinal Cord Injury Center of Heidelberg University Hospital), 8 other study centres are initiated and open for recruitment (Kliniken Schmieder, Heidelberg; Heinrich-Sommer-Klinik, Bad Wildbad; Sankt-RochusKlinik, Bad Schönborn; SRH Gesundheitszentrum Bad Wimpfen; Neurologisches Zentrum, Segeberger Kliniken $\mathrm{GmbH}$, Bad Segeberg; August-Bier-Klinik, Bad Malente; Klinikum Bad Bramstedt GmbH, Bad Bramstedt; BG Klinikum Hamburg). Three centers are dedicated spinal cord injury centers and six centers are neurorehabilitation hospitals.

\section{Participants}

Suitable study participants are to be identified, screened, and recruited in one of the 9 study centers at the end of acute rehabilitation.

\section{Inclusion criteria}

1) Patients with SCI or stroke at the end of initial inpatient treatment

2) Age between 18 and 85 years

3) At least minimal impairment of walking ability (score of $\leq 4$ at item 8 in the mRMI): If the patient manages a flight of stairs independently (score of 5 ) without any aids or appliances, the patient cannot be enrolled

4) Wheelchair mobility (manual or electric wheelchair) achieved

5) Ability to follow study procedures (tablet usability, WLAN access guaranteed at least once a week)

6) Patients' ability to consent

7) Written informed consent

\section{Exclusion criteria}

1) Serious psychiatric illness (e.g. schizophrenia, persistent suicidal tendencies)

2) Dependence on mechanical ventilation for respiration

3) Impairment of walking ability/mobility due to prior stroke
4) Lack of independent mobility prior to study entry (equivalent to $\mathrm{mRS}=5$ )

5) Any physical or mental limitations that significantly restrict the adherence to the study procedures

6) Severe cognitive deficits

\section{Outcome measures}

\section{Primary outcomes}

1) Objective measurement of mobility (walking distance and/or wheelchair distance) in everyday life of patients utilizing instrumented activity tracking in the ambulatory sector

2) Structured ICF-based assessment of rehabilitation care on mobility parameters in the ambulatory sector with particular focus on the ICF level of participation (i.e., in a real-life situation)

3) Evaluation of treatment goal agreement between patients and health care providers

4) Evaluation of treatment goal attainment in patients and health care providers, respectively

\section{Secondary outcomes}

1) Documentation of ambulatory mobility-related rehabilitation interventions (physical therapy, wheelchair features)

2) Assessment of the individual ambulatory rehabilitation care network of patients

3) Measuring the degree of coordination of health care interventions with a particular focus on ambulatory physical therapy

\section{Data collection}

\section{Data management system}

The NeuroMoves project introduces a novel ITsupported patient management platform consisting of innovative monitoring tools based on instrumented activity tracking and web-based data collection options for patients and therapists. This platform is intended to ensure the most efficient and easy-to-handle data acquisition, technical and application-related interoperability, and data security for patients as well as health care service providers. This IT-platform forms the basis for a fast translation of the study results into a new standard of ambulatory care, where for example activity tracking might serve as an "early warning system" indicating a deterioration in mobility that might require medical attention. The results of the assessments collected at the visit time points are entered into the database by the investigators via a web client (Fig. 1). The IT-platform is fully compatible with the General Data Protection Regulation (GDPR). 


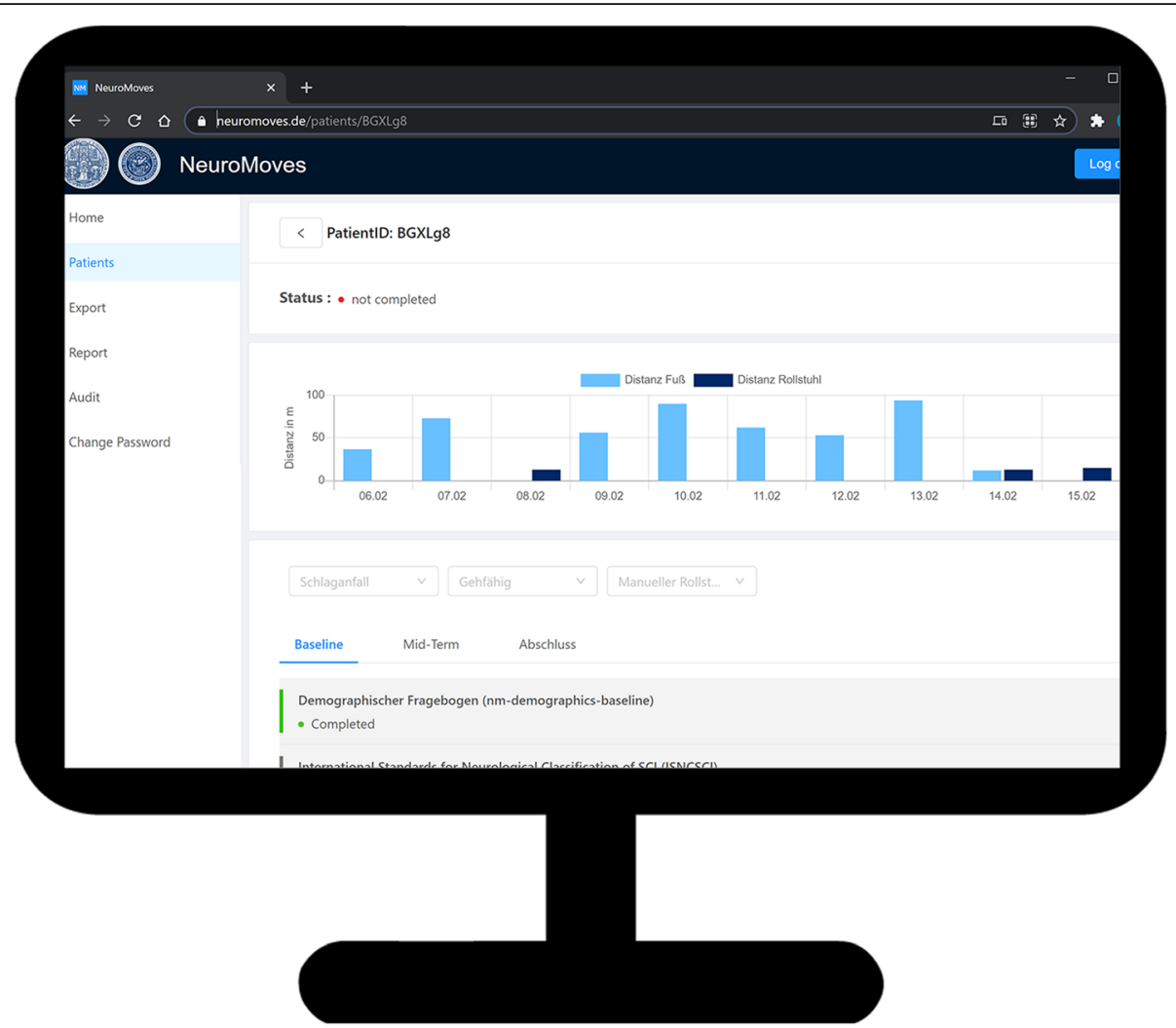

Fig. 1 For illustration purposes the main page of the study management system which can be accessed via a web-client ist depicted. On the patients tab, the study subject can be selected using a pseudonymized patient ID. The investigators can follow-up on the mobility status over the last few days which is presented separately for distances covered by foot or wheelchair, respectively

\section{Measures}

After a potential candidate agrees to participate in the study, appropriate assessments (Table 1: NeuroMoves visit schedule; Fig. 2: study flowchart) are collected at three time points (baseline, midterm, final visit) within the 8-months observation period. The baseline visit takes place in the clinic at the end of inpatient care or within the first 6 weeks thereafter. For the midterm and final visits (and where required the baseline visit), study participants are asked to attend outpatient appointments at the respective study center.

\section{Instrumented activity tracking}

During the baseline visit, study participants will receive a sensor and a tablet-computer for activity tracking (Fig. 3). While the tablet is needed only once a day to transmit the accumulated sensor data, the sensor must be permanently fixed to the shoe or the wheelchair to capture the activity of a whole day. The distance traveled per day is calculated by validated algorithms utilizing the raw data of an inertial motion sensor (IMU) integrating a triaxial accelerometer (acceleration) and a gyroscope (orientation/rotational movement).
Mobility data can be monitored after upload via the study management system by the responsible investigators. In case, the captured mobility data deviates massively from baseline values, or no data is uploaded over a substantial period, the responsible investigator will contact the study participant by email or phone to identify possible reasons.

Mobility patterns with respect to the proportion of safe/unsafe walkers or predominant wheelchair users in the ambulatory sector after stroke or SCI have not been systematically analyzed. In our expert opinion, three major mobility patterns can be expected among the study participants:

- Predominant and safe walkers (hereafter referred to as pedestrians) who do not need a wheelchair or use it only on very rare occasions. These are, for example, stroke patients with mild hemiparesis, who usually walk independently and do not use a wheelchair.

- Predominant wheelchair users (hereafter referred to as wheelchair users), who are not able to walk at all or only in a therapeutic setting. These are, for example, people with complete loss of function of 
Table 1 NeuroMoves visit schedule: within the 8-months observation period, the following assessments are collected at 3 visits: International Standards for Neurological Classification of Spinal Cord Injury (ISNCSCI), Spinal Cord Independence Measure (SCIM) III, National Institutes of Health Stroke Scale (NIHSS), modified Rankin Scale (mRS), Barthel Index (BI), functional independence measure (FIM), modified Rivermead Mobility Index (mRMI), 10-m walking test (10mWT), Timed up and go Test (TUG), Wheelchair Skills Test Questionnaire (WST-Q), Wheelchair Questionnaire, Depressions Anxiety and Stress Scale (DASS), World Health Organization Quality of Life Brief Version and disabilities module (WHOQOL-BREF-DIS), Questionnaire of individual care networks

\begin{tabular}{|c|c|c|c|}
\hline Assessment & Baseline & Midterm 4 months \pm 2 weeks & Final 8 months \pm 2 weeks \\
\hline Demographics & $\mathrm{X}$ & $\mathrm{X}$ & $\mathrm{x}$ \\
\hline \multicolumn{4}{|l|}{ Functional assessments/Questionnaires } \\
\hline \multicolumn{4}{|l|}{ SCI } \\
\hline ISNCSCI: sensory and motor scores & $\mathrm{x}$ & & $\mathbf{x}$ \\
\hline SCIM & $\mathrm{x}$ & & $\mathrm{x}$ \\
\hline \multicolumn{4}{|l|}{ Stroke } \\
\hline NIHSSS & $x$ & & $x$ \\
\hline mRS & $\mathrm{x}$ & & $x$ \\
\hline \multicolumn{4}{|l|}{ Stroke\&SCI } \\
\hline $\mathrm{Bl}$ & $x$ & $x$ & $x$ \\
\hline FIM & $x$ & $\mathrm{x}$ & $\mathrm{x}$ \\
\hline $\mathrm{mRMl}$ & $x$ & $\mathrm{x}$ & $\mathrm{x}$ \\
\hline $10 \mathrm{mWT}$ & $x$ & $\mathrm{x}$ & $\mathrm{x}$ \\
\hline TUG & $\mathrm{x}$ & $\mathrm{x}$ & $\mathrm{x}$ \\
\hline WST-Q & $x$ & $\mathrm{x}$ & $\mathrm{x}$ \\
\hline Wheelchair questionnaire & $x$ & $\mathrm{x}$ & $\mathrm{x}$ \\
\hline DASS & $\mathrm{x}$ & $x$ & $\mathbf{x}$ \\
\hline WHOQOL-BREF-DIS & $\mathrm{x}$ & $\mathrm{x}$ & $\mathrm{x}$ \\
\hline Questionnaire and interview of individual care networks & & & $\mathbf{x}$ \\
\hline \multicolumn{4}{|l|}{ Training/Checkup } \\
\hline Activity tracker & $\mathrm{x}$ & $\mathrm{x}$ & $\mathrm{x}$ \\
\hline Tablet-computer & $\mathbf{X}$ & $\mathbf{x}$ & $\mathbf{x}$ \\
\hline
\end{tabular}

the lower extremities after severe SCI or severe hemiparesis after stroke.

- Study participants who are capable of both, walking and using the wheelchair to achieve mobility (hereafter referred to as borderline walkers). These are people with e.g. incomplete SCI or moderate hemiparesis, who walk over short distances and use the wheelchair for longer distances).

To minimize measurement inaccuracies for the sensor-based algorithms for movement or step detection, the sensor of the activity tracker is attached as follows: For wheelchair users, a clip device is attached to the wheel of the wheelchair allowing for easy fixation and removal of the sensor. For pedestrians, the sensor is attached to the shoelaces or shoe strips on the less affected leg via a clip device. In the case of borderline walkers, two clip devices are used: One is attached to the shoe of the less affected leg and the other to the wheel of the wheelchair. Since only one sensor is available per study participant, the study participants are requested to put the sensor into the clip of the device in use (either shoe or wheelchair). Based on the motion profiles recorded by the sensor, the activity tracker automatically recognizes the type of mobility (pedestrian or wheelchair).

At the end of each day, study participants must recharge the sensor by removing it from the clip and placing it on a wireless charger. If the sensor and the tablet computer are within Bluetooth transmission range during the charging process, the sensor data is automatically uploaded to the tablet. A wireless internet connection is required to upload the activity data from the tablet to the server of the study management system. Usually, this upload is scheduled once a day, but can also be delayed up to a week. The study participants are instructed accordingly at the baseline visit. Every 2 weeks, study participants are contacted by phone to clarify technical questions and problems. 
Patients with acute stroke or spinal cord injury

Main inclusion criteria

1)Age between $18-85$ years

2)At least minimal impairment of walking ability (score of $\leq 4$ at item 8 in the mRMI): If the patient manages a flight of stairs independently (score of 5) without any aids or appliances, the patient cannot be enrolled

3)Wheelchair mobility (manual or electric wheelchair) achieved

4)Ability to follow study procedures (tablet
Main exclusion criteria

1)Serious psychiatric illness (e.g. schizophrenia, persistent suicidal tendencies)

2)Dependence on mechanical ventilation for respiration

3)Impairment of walking ability/mobility due to prior stroke

4)Lack of independent mobility prior to study entry (equivalent to $\mathrm{mRS}=5$ )

5)Any physical or mental limitations that

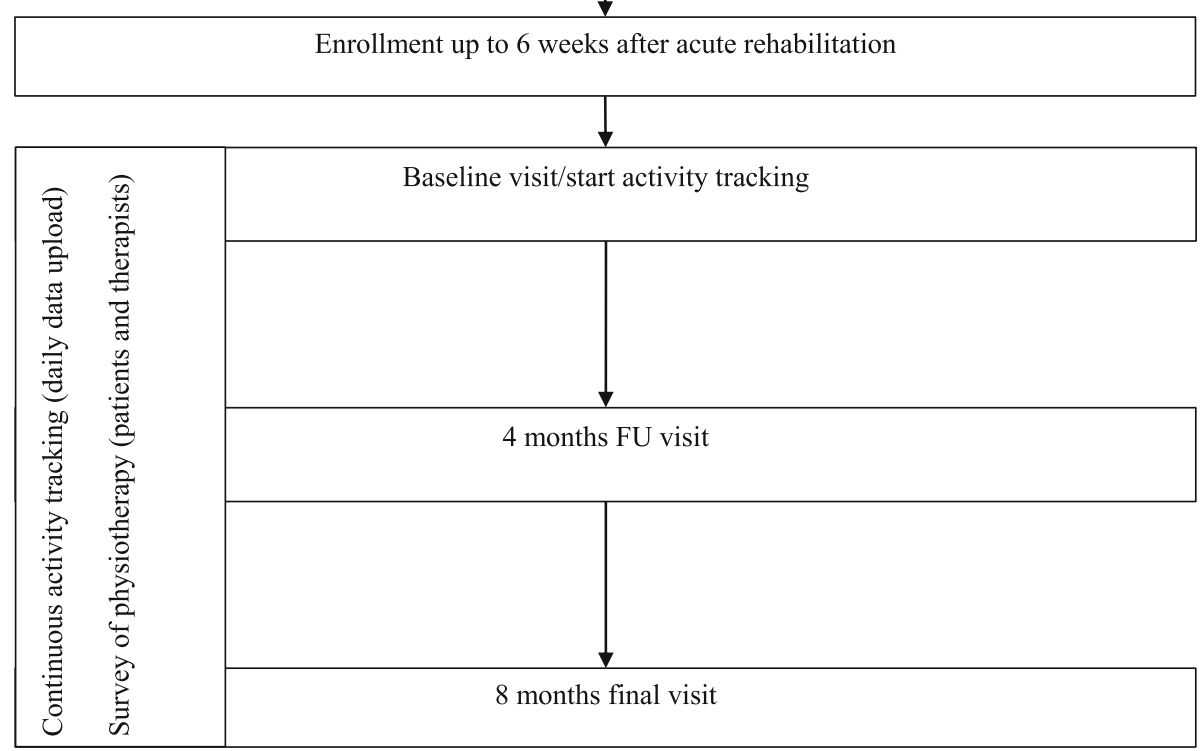

Fig. 2 Study flowchart

\section{Demographics}

Identifying data, main and relevant secondary diagnoses are collected exclusively at the baseline visit. The coding of the main diagnosis (stroke or SCI) or secondary diagnosis is based on the ICD-10 version 2019.

\section{Assessment of neurological and functional impairment}

To classify the neurological and functional impairment of the study participants, NIHSS [14] and mRS [15] will be applied at baseline and final visits for study participants with stroke. The International Standards for Neurological Classification of Spinal Cord Injury (ISNCSCI) [16] and the Spinal Cord Independence Measure (SCIM) III [17] are applied in study participants with SCI.

\section{Assessment of mobility}

1) 10MWT, TUG

The 10MWT (10-Meter Walk Test) is a mobility test that measures the time it takes a person to walk a distance of $10 \mathrm{~m}$ [18]. From this time, the self-selected walking speed is then determined. The TUG (Timed Up and Go test) is used to assess the risk of falling and the balance from sitting to standing and walking [19]. It uses the time that a person takes to rise from a chair, walk three meters, turn around, walk back to the chair, and sit down. The use of assistive devices is permitted in both tests and is documented. For patients, who are unable to walk, these tests cannot be performed. 


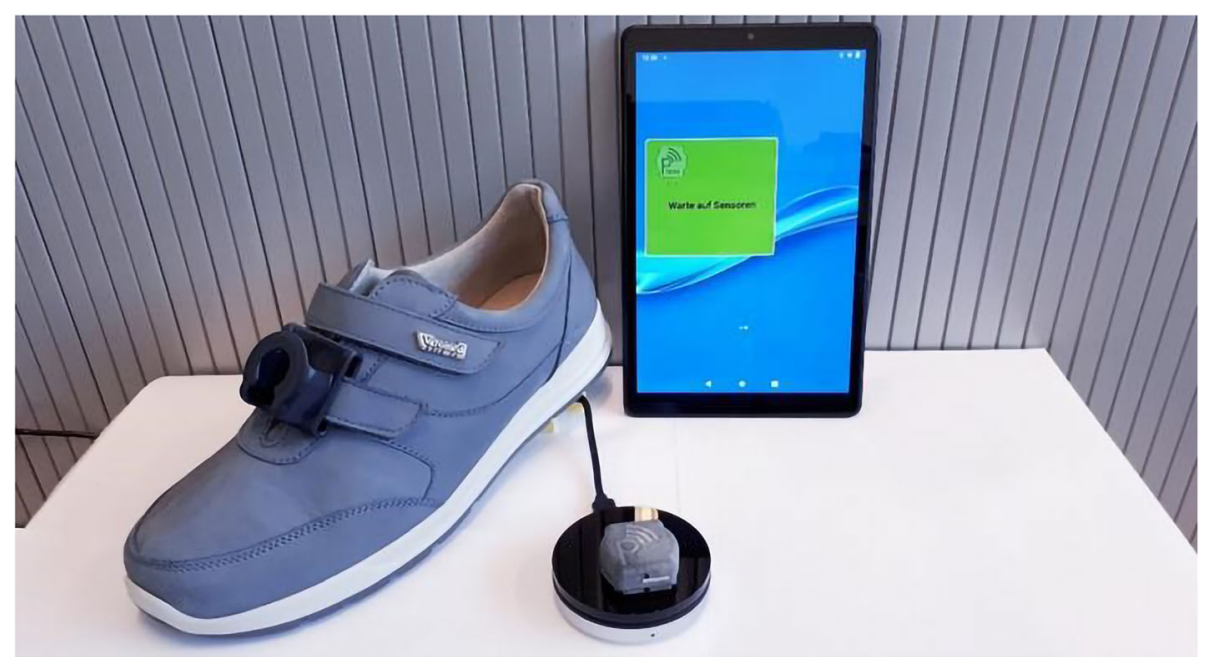

Fig. 3 Technology for activity tracking: tablet-computer, sensor with wireless charger and sensor clip for attachment to shoe

Both tests are validated for the assessment of mobility in both SCI [20] and stroke [21].

2) FIM

The FIM (Functional Independence Measure) is a measuring instrument with 18 items for the assessment of motor, cognitive, and social functions, which are evaluated by the clinician. This measuring instrument was chosen with regard to the overall cohort because, unlike the SCIM (SCI only), it has been validated for use in both stroke and SCI. The FIM reflects the current functional status of a patient and not his/her functional capacity [22].

3) mRMI

The mRMI (modified Rivermead Mobility Index) is a validated measuring instrument with 8 items for assessing mobility in stroke [23].

4) WST-Q

The validated WST-Q (Wheelchair Skills TestQuestionnaire) objectively evaluates the safety and ability of patients to handle a manual or powered wheelchair [24-26]. It is only performed on patients who are dependent on a wheelchair.

5) Wheelchair questionnaire

The questionnaire (not yet validated) created specifically for the NeuroMoves project serves to record the type of wheelchair and accessories used by study participants and is answered by the investigators. In order to record the satisfaction, the patient will answer questions regarding the importance of certain points (pain free sitting, independence and mobility) and his satisfaction with his wheelchair (supplementary file; questionnaire 1).

6) Barthel Index
The Barthel Index (BI) is a method for evaluating the everyday abilities of a patient and is used to systematically assess independence and the need for care [27]. It has been validated for both patients with SCI and stroke.

\section{Assessment of depression and quality of life}

1) DASS

The DASS (Depression Anxiety Stress Scale) is a validated screening method and measures depression, anxiety, and stress levels in the past week [28].

2) WHOQOL-BREF-DIS

The WHOQOL-BREF-DIS is an instrument for recording the subjective quality of life. It covers the areas of physical and mental well-being, social relations, and the environment. The DIS module deals with questions about physical limitations [29]. It has been validated in patients with SCI and stroke.

\section{Questionnaire and interview on the individual patient care network and coordination of care}

During the final visit, the study participants will receive a questionnaire to indicate the individual patient care network and the degree of coordinated care. The questions relate to diseases other than stroke/SCI, the visited health care providers as inpatient and during the last 8 months in the home environment, circumstances of the physical therapy (e.g. process of finding the appropriate therapist), aspects regarding quality of therapy care, the cooperation between family practitioner and physical therapist and missed services (supplementary file; questionnaire 2). 
Afterwards the participants will be invited to join an interview to explore the context and connections of factors which might influence the respective care in the ambulatory sector. The participants will be interviewed via telephone according to an interview guide. Data of the entire study sample is not manageable; therefore a purposive sampling strategy will be employed. The selection of participants is based on written consent, age, sex, stroke/SCI, study center (local distribution over Germany), mobility parameters and functional impairment. The data analysis follows the concept of qualitative content analysis [30].

\section{Patient-reported treatment goal attainment}

To record the prescriptions of physical therapy, a daily interview is automatically generated by the tablet application (Fig. 4). This so-called "evening query" starts with the recurring question of "How are you today?", which can be rated on a 5-point ordinal scale. Next, the study participant is asked whether an appointment for physical therapy is scheduled the following day. If it will be the first session of a new prescription cycle, an 11-item (5point ordinal scale for each item) questionnaire will pop up to select between 11 prespecified treatment goals (joint mobility, pain reduction, spasticity in both legs, strength and endurance, transfer, standing and balance, walking, wheelchair mobility, 3 items about mobility). If it will be the last session of a prescription cycle, the participant will be asked to evaluate the same 11 items. Moreover, the participant will be asked to rate the overall satisfaction of goal attainment on a 5-point ordinal scale. Where applicable, the query algorithm reminds the study participant to bring along the tablet to the next physical therapy session to ask for corresponding ratings by the therapist (supplementary file; questionnaire 3).

\section{Therapist-reported treatment goal attainment and treatment measures}

Similarly, the physical therapists are asked and evaluated about treatment goals for the upcoming prescription cycle on this 11-item questionnaire via the tablet of the participant (joint mobility, pain reduction, spasticity in both legs, strength and endurance, transfer, standing and balance, walking, wheelchair mobility, 3 items about mobility). Additionally, at the last treatment session, the therapist will be asked about the treatment setting (controlled environment (e.g. physical therapy practice), real-life simulation environment (e.g. stairs in physical therapy practice), or real-life situation (e.g. participants' home, public transportation) and the applied treatment measures (e.g. joint mobilization, endurance training, strength training, sitting balance, standing balance, gait training, transfer-/wheelchair-training, coordination).
Finally, the therapist will be asked to quantify the training intensity (dose) on a visual analogue scale (supplementary file; questionnaire 4).

\section{Statistical procedures}

Primary outcome (1), which represents the basis for the sample size calculation, will be analyzed using multiple linear mixed regression methods for repeated measures. For these regression analyses, the primary outcome (1) is defined as the change in the daily distance covered between baseline and final visit after 8 months. To account for day-to-day fluctuations as well as for acclimatization effects during the transition between acute rehabilitation and settling into the home environment, the baseline mobility measurement is defined as the daily distance averaged over the second week after start of mobility recording, i.e. day 8-14 after baseline (up to 6 weeks after discharge from acute rehabilitation). Because we expect a significant number of participants in older age groups with difficulties to master the required technology, this approach allows for an extra week of getting accustomed to the activity tracker technology in both groups. For the final mobility measurement, we will use the daily distance averaged over the final week prior to the last study visit. The utilization of such statistical models allows for adjustments of confounding variables (e.g. daily mobility at baseline, number of treatment sessions, or severity of the neurological disorder). Moreover, linear mixed models are also quite robust and statistically more powerful with respect to missing data of repeated measurements (under the assumption of missing at random). Additionally, hitherto not further prespecified statistical analyses on the repeated mobility measurements are planned (e.g. individual continuous trajectories, bouts of mobility).

As the main predictor variable for the primary outcome (1) and basis for our sample size considerations, we will use the primary outcome (2) "degree of participation" of the physical therapy, which has been carried out during the 8 months study period. The answers of the therapist at the end of each prescription cycle to the itemized questionnaire on the patient tablet are the basis for an evaluation of the "degree of participation" of therapy, ranging from 0 to $100 \%$ of all treatment session.

Primary outcome (3) focuses on the agreement of treatment goals between patients and therapists. The itemized questionnaires between patients and therapists will be analyzed by intraclass-correlation methods. The resulting correlation coefficients indicate the degree of agreement concerning treatment goals between patients and therapists. Resulting agreement measures can serve for further exploratory analyses (e.g. subgrouping, use as confounding/explanatory variable in exploratory regression 


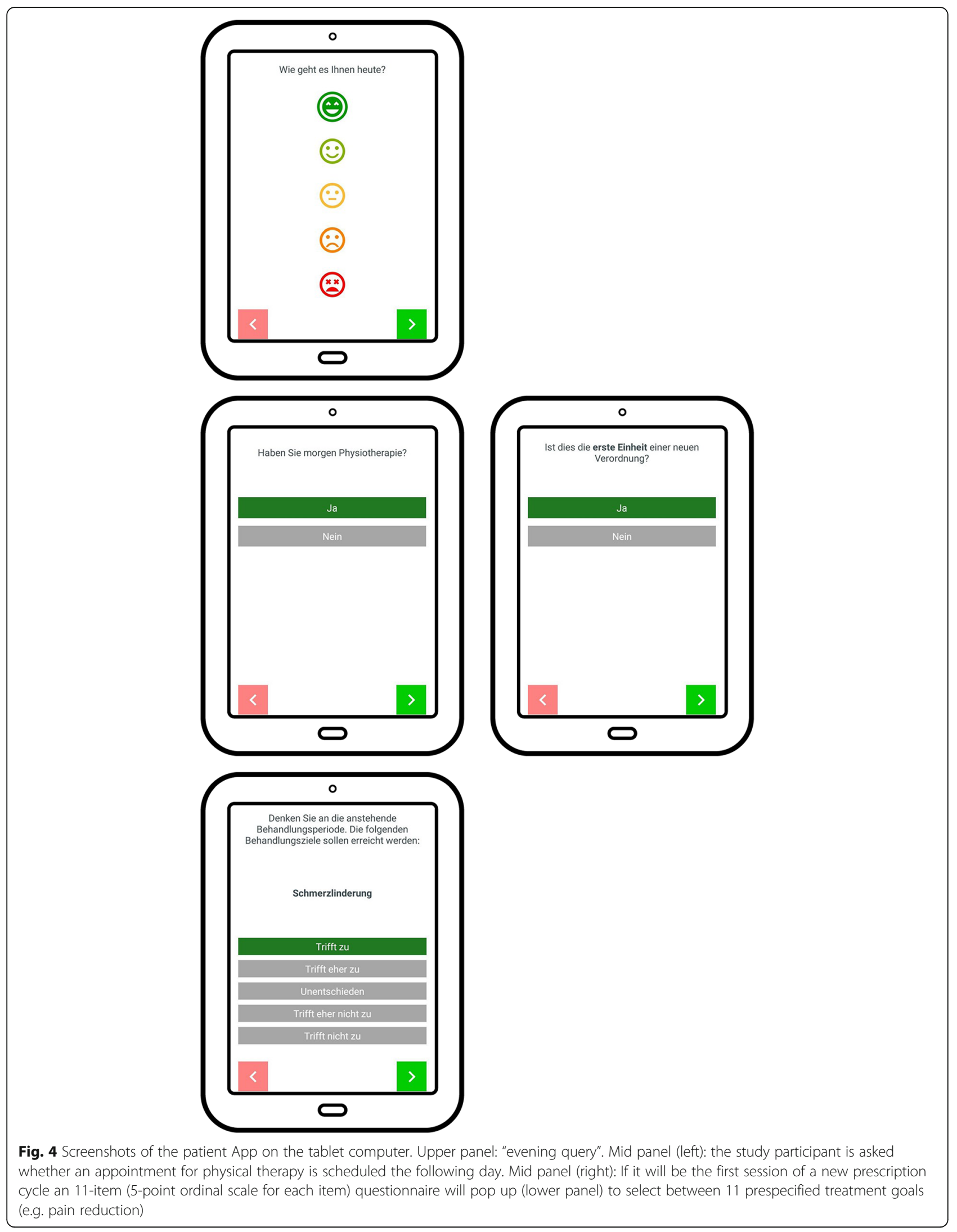


analyses, use as explanatory variable for quality of life measures, etc.).

Primary outcome (4) represents goal attainment analysis related to either patients or therapists, respectively. Subjectively highly ranked treatment goals are subject to requery at the end of each prescription cycle. The requery is performed via itemized questionnaires. Sum scores of items (item on 5-point ordinal scale) indicate the degree of goal attainment. Results serve for further exploratory analyses, e.g. as explanatory variable for functional outcomes, quality of life measures, etc.).

Secondary outcomes are evaluated with descriptive analysis.

\section{Sample size}

The sample size calculation is based on the primary endpoint (1): the change of daily distance covered in meters between baseline and 8 months. The main predictor variable is the primary outcome (2) "degree of participation" on a scale from 0 to $100 \%$. For study participants with SCI, the daily distance traveled is assumed to be $2000 \mathrm{~m}$ with a standard deviation of $2100 \mathrm{~m}$ on average, and for stroke survivors, the daily distance traveled is assumed to be $1586 \mathrm{~m}$ with a standard deviation of $1797 \mathrm{~m}$ on average [31,32]. We assume that the study population will be composed of approximately $70 \%$ stroke survivors and $30 \%$ patients with SCI. We assume the same treatment effect of "the degree of participation" in both patient populations. For the overall sample size, the weighted mean is thus approximately $1700 \mathrm{~m}$ with a standard deviation of $\sigma \mathrm{Y}=1900 \mathrm{~m}$. From a standard deviation of the predictor of $\sigma \mathrm{X}=35.36$ percentage points (based on the standard deviation of a non-informative Jeffrey's Prior of the beta distribution, since there is no prior knowledge about the distribution of the predictor namely the "degree of participation"), it can be shown in a simple linear regression model with a case number of 500 patients that the regression coefficient $\beta X$ for the main predictor differs from 0 , assuming that under the alternative hypothesis the main predictor is at $\beta X=7.05$ $\mathrm{m}$ of additionally traveled daily distance per percentage point of participation-oriented therapy (i.e. from 0 to $100 \%$ "degree of participation" would have an effect of approx. $700 \mathrm{~m}$ ). We assume a dropout rate of $10 \%$, a standard deviation of the primary outcome of $1900 \mathrm{~m}$, a power of $80 \%$, and a two-sided significance level of $5 \%$. Using a linear mixed model and the addition of further positively correlated primary outcome measures is expected to increase power. This also applies to the additional inclusion of control variables as independent predictors in the statistical model, which we expect to explain an additional portion of the variance and thus lead to increased power. The number of cases was planned according to the method of Neter et al. [33] and the software PASS 14.0.

\section{Discussion}

The study will evaluate factors that are associated with changes of mobility in the ambulatory setting over 8 months after discharge from acute rehabilitation in stroke and SCI patients. NeuroMoves is intended as a national multicenter observational cohort study with 9 clinical sites in Germany. Through the analysis of the current status of care at the transition between hospital and ambulatory care, the project intends to identify implementation insufficiencies in the ambulatory delivery of rehabilitation services with a particular focus on the therapeutic level of participation according to the ICF. To the best of our knowledge, there are no systematic analyses in large patient cohorts, neither nationally nor internationally, to investigate the implementation of ambulatory rehabilitation interventions.

The findings could inform healthcare decision-making regarding ambulatory care in Germany focusing on mobility-promoting interventions for patients with mobility-restricting paralysis syndromes.

\section{Abbreviations \\ 10mWT: 10-m walk test; ASIA: American Spinal Injury Association; BI: Barthel Index; CNS: Central nervous system; DASS: Depressions-Angst-Stress-Skalen; FIM: Functional Independence Measure; GB-A: Gemeinsamer \\ Bundesausschuss; ICD-10: International Classification of Diseases - Version 10; ICF: International Classification for Functioning, Disability and Health; ICH- GCP: International Council for Harmonisation - good clinical practice; IMU: Inertial motion sensor; ISNCSCI: International Standards for Neurological Classification of Spinal Cord Injury; IT: Information Technology; mRMI: Modified Rivermead Mobility Index; mRS: Modified Rankin Score; NIHS S: National Institute of Health Stroke Scale; SCl: Spinal Cord Injury; SCIM: Spinal Cord Independence Measure; SGB: Sozialgesetzbuch; SOP: Standard Operating Procedure; TUG: Timed Up and Go Test; WHOQOL- BREF: World Health Organization Quality of Life abbreviated 26 item version; WHOQOL-DIS: World Health Organization Quality of Life Disability Module; WLAN: Wireless Local Area Network; WST-Q: Wheelchair Skills Test - Questionnaire}

\section{Supplementary Information}

The online version contains supplementary material available at https://doi. org/10.1186/s12883-021-02167-y.

Additional file 1. Questionnaires developed for this study.

\section{Acknowledgments}

Not applicable.

\section{Authors' contributions}

RR and NW wrote the initial NeuroMove proposal to the G-BA. AH, NW, RR, SF and TS worked on the compilation of the final study protocol. $A H, C H, L H$, TS, SF and NW worked on the compilation of the study-specific assessments. $\mathrm{AH}$ and TS drafted the first version of the manuscript. All authors reviewed and approved the final manuscript.

\section{Funding}

Innovationsfond at Gemeinsamer Bundesausschuss, Funding code 01VSF18032, approval period 01.05.2019 to 30.04.2022. 
The funding body has no role in the design of the study, the collection, analysis, and interpretation of data and in writing the manuscript. Open Access funding enabled and organized by Projekt DEAL.

\section{Availability of data and materials}

Data sharing is not applicable to this article as no datasets were generated yet.

\section{Declarations}

\section{Ethics approval and consent to participate}

The study was initially approved by the Ethics Committee of the Medical Faculty Heidelberg with the approval-ID S-858/2019 and later by the ethics committees responsible for each of the participating centers. Written informed consent from each patient will be obtained prior to any study related procedure.

\section{Consent for publication}

Not applicable.

\section{Competing interests}

The authors $\mathrm{AH}, \mathrm{TS}, \mathrm{CH}, \mathrm{SF}, \mathrm{TD}, \mathrm{LH}, \mathrm{MW}, \mathrm{RR}$, and NW declare that they have no competing interests.

\section{Author details}

'Spinal Cord Injury Center, Heidelberg University Hospital, Schlierbacher Landstraße 200a, 69118 Heidelberg, Germany. ${ }^{2}$ Department of General Practice and Health Services Research, Heidelberg University Hospital, Heidelberg, Germany.

Received: 19 February 2021 Accepted: 23 March 2021 Published online: 07 April 2021

\section{References}

1. Behrens J, Busch I, Grand HJ, Heidt S, Breuer C, Glaesener J, et al. Zur Bedeutung der Heilmittel für die Förderung der Teilhabe unter Berücksichtigung des Auftrags therapeutischer Fachberufe - ein Beitrag zur aktuellen Diskussion. 2016. Available from: https://www.dvfr.de/fileadmin/ user_upload/DVfR/Downloads/Stellungnahmen/Heilmittel-Ausschuss_ Expertise.pdf.

2. Silva SM, Correa FI, Faria CD, Buchalla CM, Silva PF, Correa JC. Evaluation of post-stroke functionality based on the international classification of functioning, disability, and health: a proposal for use of assessment tools. J Phys Ther Sci. 2015;27(6):1665-70. https://doi.org/10.1589/jpts.27.1665.

3. Steiner WA, Ryser L, Huber E, Uebelhart D, Aeschlimann A, Stucki G. Use of the ICF model as a clinical problem-solving tool in physical therapy and rehabilitation medicine. Phys Ther. 2002;82(11):1098-107. https://doi.org/1 0.1093/ptj/82.11.1098.

4. Stähler T, Krenz S, Backes I. Empfehlungen für die phase E der neurologischen rehabilitation. 2013. Available from: https://www.bar-fra nkfurt.de/fileadmin/dateiliste/_publikationen/reha_vereinbarungen/pdfs/BA REmpfPhaseE7.1.web.pdf.

5. Meyer S, Verheyden G, Brinkmann N, Dejaeger E, De Weerdt W, Feys H, et al. Functional and motor outcome 5 years after stroke is equivalent to outcome at 2 months: follow-up of the collaborative evaluation of rehabilitation in stroke across Europe. Stroke. 2015;46(6):1613-9. https://doi. org/10.1161/STROKEAHA.115.009421.

6. DeJong G, Tian W, Hsieh CH, Junn C, Karam C, Ballard PH, et al. Rehospitalization in the first year of traumatic spinal cord injury after discharge from medical rehabilitation. Arch Phys Med Rehabil. 2013;94(4 Suppl):S87-97. https://doi.org/10.1016/j.apmr.2012.10.037.

7. Dennis MS, Lo KM, McDowall M, West T. Fractures after stroke: frequency, types, and associations. Stroke. 2002;33(3):728-34. https://doi.org/10.1161/ hs0302.103621.

8. Middleton JW, Lim K, Taylor L, Soden R, Rutkowski S. Patterns of morbidity and rehospitalisation following spinal cord injury. Spinal Cord. 2004;42(6): 359-67. https://doi.org/10.1038/sj.sc.3101601

9. Holliday RC, Cano S, Freeman JA, Playford ED. Should patients participate in clinical decision making? An optimised balance block design controlled study of goal setting in a rehabilitation unit. J Neurol Neurosurg Psychiatry. 2007;78(6):576-80. https://doi.org/10.1136/jnnp.2006.102509.
10. Payton OD, Nelson CE, Hobbs MSC. Physical therapy patients' perceptions of their relationships with health care professionals. Physiotherapy Theory and Practice. 1998;14(4):211-21. https://doi.org/10.3109/09593989809057167.

11. Wallesch C, Mokrusch T. Stellungnahme der DGNR zur Ausbildung "Neurophysiotherapie". 2014. Available from: https://www.physio-akademie. de/fileadmin/user/franzi/pdf/Menue_2_Kurse_Fortbildungen/Neurorehabilita tion/Stellungnahme_DGNR_2015.pdf.

12. Wallace MA, Kendall MB. Transitional rehabilitation goals for people with spinal cord injury: looking beyond the hospital walls. Disabil Rehabil. 2014; 36(8):642-50. https://doi.org/10.3109/09638288.2013.805259.

13. Vandenbroucke JP, von Elm E, Altman DG, Gotzsche PC, Mulrow CD, Pocock $\mathrm{SJ}$, et al. Strengthening the reporting of observational studies in epidemiology (STROBE): explanation and elaboration. PLoS Med. 2007:4(10): e297. https://doi.org/10.1371/journal.pmed.0040297.

14. Brott T, Marler JR, Olinger CP, Adams HP Jr, Tomsick T, Barsan WG, et al. Measurements of acute cerebral infarction: lesion size by computed tomography. Stroke. 1989;20(7):871-5. https://doi.org/10.1161/ 01.STR.20.7.871

15. Rankin J. Cerebral vascular accidents in patients over the age of 60 . II Prognosis Scott Med J. 1957;2(5):200-15. https://doi.org/10.1177/0036933 05700200504.

16. Kirshblum SC, Burns SP, Biering-Sorensen F, Donovan W, Graves DE, Jha A, et al. International standards for neurological classification of spinal cord injury (revised 2011). J Spinal Cord Med. 2011;34(6):535-46. https://doi.org/1 $0.1179 / 204577211 \times 13207446293695$.

17. Itzkovich M, Gelernter I, Biering-Sorensen F, Weeks C, Laramee MT, Craven BC, et al. The spinal cord Independence measure (SCIM) version III: reliability and validity in a multi-center international study. Disabil Rehabil. 2007; 29(24):1926-33. https://doi.org/10.1080/09638280601046302.

18. Rossier P, Wade DT. Validity and reliability comparison of 4 mobility measures in patients presenting with neurologic impairment. Arch Phys Med Rehabil. 2001;82(1):9-13. https://doi.org/10.1053/apmr.2001.9396.

19. Podsiadlo D, Richardson S. The timed "up \& go": a test of basic functional mobility for frail elderly persons. J Am Geriatr Soc. 1991;39(2):142-8. https:// doi.org/10.1111/j.1532-5415.1991.tb01616.x.

20. van Hedel HJ, Wirz M, Dietz V. Assessing walking ability in subjects with spinal cord injury: validity and reliability of 3 walking tests. Arch Phys Med Rehab. 2005;86(2):190-6. https://doi.org/10.1016/j.apmr.2004.02.010.

21. Flansbjer UB, Holmback AM, Downham D, Patten C, Lexell J. Reliability of gait performance tests in men and women with hemiparesis after stroke. J Rehabil Med. 2005;37(2):75-82.

22. Granger CV, Hamilton BB, Keith RA, Zielezny M, Sherwin FS. Advances in functional assessment for medical rehabilitation. Topics Geriatric Rehabil. 1986;1(3):59-74. https://doi.org/10.1097/00013614-198604000-00007.

23. Lennon S, Johnson L. The modified rivermead mobility index: validity and reliability. Disabil Rehabil. 2000;22(18):833-9. https://doi.org/10.1080/096382 80050207884.

24. Mountain AD, Kirby RL, Smith C. The wheelchair skills test, version 2.4: validity of an algorithm-based questionnaire version. Arch Phys Med Rehabil. 2004;85(3):416-23. https://doi.org/10.1016/50003-9993(03)00427-1.

25. Rushton PW, Kirby RL, Miller WC. Manual wheelchair skills: objective testing versus subjective questionnaire. Arch Phys Med Rehabil. 2012;93(12):2313-8. https://doi.org/10.1016/j.apmr.2012.06.007.

26. Rushton PW, Kirby RL, Routhier F, Smith C. Measurement properties of the wheelchair skills test-questionnaire for powered wheelchair users. Disab Rehabil Assist Technol. 2016;11(5):400-6. https://doi.org/10.3109/17483107.2 014.984778.

27. Mahoney FI, Barthel DW. Functional evaluation: the Barthel index. Md State Med J. 1965;14:61-5

28. Nilges P, Essau C. Depression, anxiety and stress scales: DASS--A screening procedure not only for pain patients. Schmerz. 2015;29(6):649-57. https:// doi.org/10.1007/s00482-015-0019-z

29. Power MJ, Green AM, Group WH-D. Development of the WHOQOL disabilities module. Qual Life Res. 2010;19(4):571-84. https://doi.org/10.1007/ s11136-010-9616-6.

30. Emerson RM, Fretz RI, Shaw LL. Writing ethnographic fieldnotes. 2nd ed. Chicago: The University of Chicago Press; 2011. p. 289.

31. Lemay V, Routhier F, Noreau L, Phang SH, Ginis KA. Relationships between wheelchair skills, wheelchair mobility and level of injury in individuals with spinal cord injury. Spinal Cord. 2012;50(1):37-41. https:// doi.org/10.1038/sc.2011.98. 
32. Mahendran N, Kuys SS, Brauer SG. Accelerometer and global positioning system measurement of recovery of community ambulation across the first 6 months after stroke: an exploratory prospective study. Arch Phys Med Rehabil. 2016;97(9):1465-72. https://doi.org/10.1016/j.apmr.2016.04.013.

33. Neter J, Wassermann W, Kutner MH. In: Irwin, editor. Applied linear regression models. 2nd ed; 1989.

\section{Publisher's Note}

Springer Nature remains neutral with regard to jurisdictional claims in published maps and institutional affiliations.

Ready to submit your research? Choose BMC and benefit from:

- fast, convenient online submission

- thorough peer review by experienced researchers in your field

- rapid publication on acceptance

- support for research data, including large and complex data types

- gold Open Access which fosters wider collaboration and increased citations

- maximum visibility for your research: over $100 \mathrm{M}$ website views per year

At BMC, research is always in progress.

Learn more biomedcentral.com/submissions 